\title{
A One Year Monitoring Study on Cardio Respiratory Fitness and Anthropometric Parameters in Soccer Players Aged 18 Years
}

\author{
Kuriu. A
}

Birce. A

\author{
Spahiu. M \\ Sports University of Tirana, Street Muhamet Gjollesha, Tirana, Albania
}

Doi:10.5901/ajis.2015.v4n2p199

\begin{abstract}
Introduction. Research for years has indicated the role that aerobic fitness plays on soccer game and its positive effects. The aim of the current study is to monitor anthropometric parameters and cardiorespiratory fitness in youth soccer players during one year. Methods. The participants were 76 youth soccer players aged 16-18 $( \pm 2.64)$ years. The players were members of five soccer clubs from the youth championship of Albania. All youth members were engaged in formal training (3-4 sessions/week; 90-120 min/ sessions) and had competed for at least 3 years. Subject were measurement (anthropometrics and cardiorespiratory fitness) at time 1 during year 2013 and the second measurement at time 2 during year 2014. Results. The improvement in cardiorespiratory fitness were statistical significant (1.7 ml/kg/min) at level of 95 percent level of confidence (cardiorespiratory fitness at $p=0.004)$. Descriptive statistics showed higher values regarding anthopometrics but this increase were not statistically significant. Conclusion. In conclusion, we propose that in other study it will be needed to have a control group in order to compare this data (control group who do not train) with those who train and to have the real improvement by the soccer training sessions. Therefore, the assessment of the soccer player's aerobic performance could be of interest for soccer coaches in order to evaluate and better programme their endurance training sessions.
\end{abstract}

Keywords: soccer, youth players, cardiorespiratory fitness, anthopometrics

\section{Introduction}

In youth, cardio respirator fitness increases as a function of body weight (Armstrong \& Welsman, 1994; Jarani and Spahi, 2014), regardless participation in any physical training Malina et al., 2004) and especially in boys. Research for years have indicated the role that aerobic fitness plays on soccer game and its positive effects (Apor, 1988; Wisloff et al., 1988). Cardiorespiratory fitness is normally tested in the laboratory using advanced equipment for gas and ventilatory measurements (Leger et al., 1988; Leger and Boucher, 1980). Such tests are not available to all teams, and several field tests that are supposed to reflect aerobic performance have been proposed (Bangsbo, 1994; Kemi et al., 2003)

A study by Helgerud et al., (2001), have demonstrated that improved maximum oxygen uptake (VO2max) and running economy, by about $5 \mathrm{ml} / \mathrm{kg} / \mathrm{min}$ and $7 \%$, respectively, affect the performance of both technique and tactics in soccer game for individual players.

Cardiorespiratory fitness shows an increase with chronological age from 8-16 years, with an accelerated increase after 10 years of age (Malina et al., 2004). The increase (aerobic capacity) in youth is strongly correlated with increases in body weight which, among other factors, are connected to growth-related changes in lungs, heart and skeletal muscle mass (Rowland, 2005). Thus the players' cardio respiratory fitness level certainly shows an important role in modern soccer and has a major influence on their technical performance and tactical choices. The aim of the current study is to monitor anthropometric parameters and cardiorespiratory fitness in youth soccer players during one year.

\section{Methods}

\subsection{Subjects}

The sample included 76 youth soccer players aged 16-18 ( \pm 2.64$)$ years. The players were members of five soccer clubs from the youth championship of Albania. All youth members were engaged in formal training (3-4 sessions/week; 90-120 
$\mathrm{min} /$ sessions) and had competed for at least 3 years. At the time of the assessments, no team players suffered from diseases.

Subject were measurement at time 1 during year 2013 and the second measurement at time 2 during year 2014. Participants were fully informed about the procedures of the study and their parents provided written informed consent.

\subsection{Measurement}

Body height and weight were assessed in all participants that took part in this study. BMI was calculated with the usual formula (body weight- $\mathrm{kg} /$ body height- $\mathrm{m} 2$ ).

Cardiorespiratory fitness was determined using an incremental running test on a ergo meter bicycle to voluntary exhaustion. Participants started at $2.2 \mathrm{~m} / \mathrm{s}$ with subsequent increments of $0.2 \mathrm{~m} / \mathrm{s}$ every minute until exhaustion. Expired oxygen (02) and carbon dioxide (CO2) flow and concentrations were measured using an open circuit breath by-breath automated gas analyser. Calibration and ambient air measurements were conducted before

\subsection{Statistical analyses}

Descriptive statistics were calculated for all variables assessed in this monitoring study. In depended samples t-tests were used to compare anthropometrics variables (body height, weight and BMI) and cardio respiratory fitness. The data were entered in the excel file and then trasfered in SPSS database using the software. All the data were analysis using SPSS program.

Finally, if measurement differences were normally distributed, reliability was assessed using the standard error of measurement and $95 \%$ limits of agreement.

\section{Results}

Data from table 1 show descriptive statistics for anthropometrics and cardio respiratory fitness In two time measurement for the number of participant, minimum and maximum values, mean and standard deviation. Number of participant during Time 1 measurement on year 2013 was 76 soccer players while in Time 2 measurement on year 2014 was 75 players. Only one player were missing during Time 2 measurement for injury reasons.

Table 1. Descriptive statistics for anthropometrics and cardio respiratory fitness

\begin{tabular}{|ccccccc|}
\hline \multicolumn{2}{|c}{ Measurement } & N & Minimum & Maximum & Mean & Std. Deviation \\
\hline year 2013 & Height & 76 & 1.19 & 1.84 & 1.6636 & 0.12521 \\
\hline Weight & 76 & 25 & 78 & 55.24 & 11.8538 \\
\hline BMl & 76 & 15.79 & 24.96 & 19.6972 & 2.21931 \\
\hline Vo2max & 76 & 24 & 60 & 54.797 & 3.8496 \\
\hline year 2014 & Valid N (listwise) & 76 & & & & \\
\hline & Height & 75 & 1.43 & 1.89 & 1.6909 & 0.08933 \\
\hline Weight & 75 & 39 & 89 & 58.411 & 10.2219 \\
\hline BMl & 75 & 16 & 30.33 & 20.3344 & 2.60144 \\
\hline Vo2max & 75 & 48 & 65 & 56.52 & 2.7048 \\
\hline
\end{tabular}

Table 2 show results for anthopometrics assessment (height, weight and BMl calculation). The height on Time 1 measurement was $1.66 \mathrm{~m}$ and Time 2 measurement was $1.69 \mathrm{~m}$. Results for weight were ( $55.2 \mathrm{~kg} ; 58.4 \mathrm{~kg}$ ) and for BMI values $(19.6 ; 20.3 \mathrm{~kg} / \mathrm{m} 2)$. 
Table 2. Descriptive statistics for anthropometrics

\begin{tabular}{|cccccc|}
\hline & Measurement & N & Mean & Std. Deviation & Std. Error Mean \\
\hline Height & year 2013 & 76 & 1.6636 & 0.12521 & 0.01771 \\
\hline & year 2014 & 75 & 1.6909 & 0.08933 & 0.00889 \\
\hline Weight & year 2013 & 76 & 55.24 & 11.8538 & 1.6764 \\
\hline & year 2014 & 75 & 58.411 & 10.2219 & 1.0171 \\
\hline BMli & year 2013 & 76 & 19.6972 & 2.21931 & 0.31386 \\
\hline & year 2014 & 75 & 20.3344 & 2.60144 & 0.25885 \\
\hline
\end{tabular}

Results from the table 3 show the results from comparison for anthropometrics. For all parameters like height, weight and $\mathrm{BMI}$ the improvement were statistical not accepted at 95 percent level of confidence even though they showed improvement from T1 to T2 (descriptive statistics).

Table 3. Independent Samples Test for comparison for anthopometrics

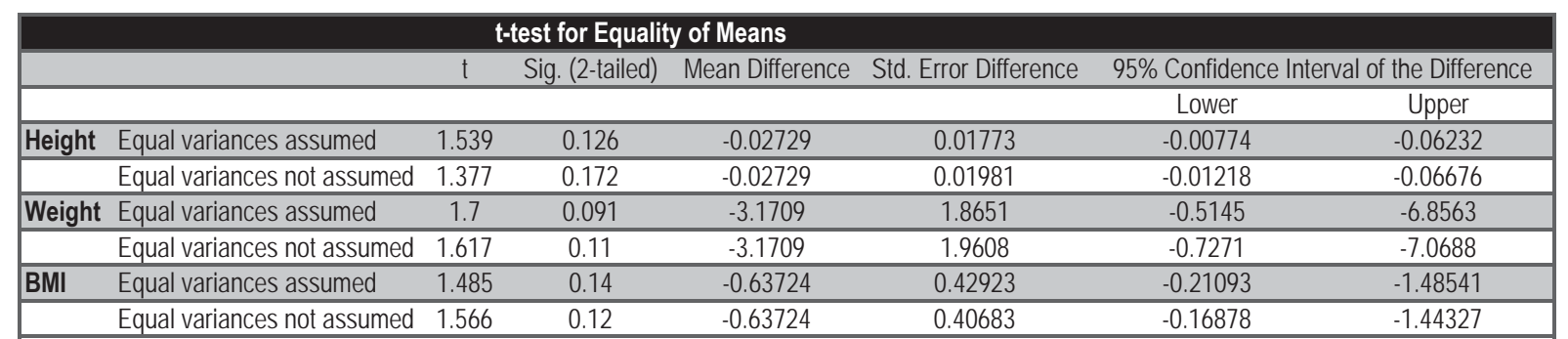

Table 4. Descriptive statistics for comparison data for cardiorespiratory fitness

\begin{tabular}{|cccccc|}
\hline & Measurement & N & Mean & Std. Deviation & Std. Error Mean \\
\hline Vo2max & year 2013 & 76 & 54.797 & 3.8496 & 0.3831 \\
\hline & year 2014 & 75 & 56.52 & 2.7048 & 0.3825 \\
\hline
\end{tabular}

Results from the table 4 and 5 show the results from descriptive statistics and comparison for cardiorespiratory fitness. For cardiorespiratory fitness the improvement were statistical accepted at 95 percent level of confidence and showed improvement from T1 to T2 ( $p=0.004)$.

Table 5. Independent Samples Test for comparison for VO2 max

\begin{tabular}{|c|c|c|c|c|c|c|}
\hline & & \multirow[t]{2}{*}{ Sig. (2-tailed) } & \multirow[t]{2}{*}{ Mean Difference } & \multirow[t]{2}{*}{ Std. Error Difference } & \multicolumn{2}{|c|}{$95 \%$ Confidence Interval of the Difference } \\
\hline & & & & & Lower & Upper \\
\hline Vo2max & Equal variances assumed & 0.004 & -1.723 & 0.6077 & -2.9239 & -0.5221 \\
\hline & Equal variances not assumed & 0.002 & -1.723 & 0.5413 & -2.7938 & -0.6521 \\
\hline
\end{tabular}

\section{Discussion}

This monitoring study showed improvement where we compare the data from year 2013 to year 2014 regarding cardiorespiratory fitness in youth soccer players in Albania. The improvement in cardiorespiratory fitness were statistical significant $(1.7 \mathrm{ml} / \mathrm{kg} / \mathrm{min})$ and level of 95 percent level of confidence (cardiorespiratory fitness at $p=0.004)$. Descriptive statistics showed higher values regarding anthopometrics but this increase were not statistically significant. Data show that cardiorespiratory fitness increases during one year of training for all participant but not for anthopometrics parameters. Data are in line with other study that show that with age this parameter (VO2 max) will increase.

We raise a question that how much cardiorespiratory will be improved by training in order to have better results in soccer. But it should be noted that the variation in estimated parameters of VO2peak may be related to sampling, testing protocols, (Malina et al., 2004). In addition, interpretation of VO2peak is confounded by variation in body size (Welsman et al., 1996). 
In the study by Helgerud et al., (2001) show that the soccer performance for technical performance and tactical aspects is affected by maximum oxygen uptake (VO2max) and running economy, by about $5 \mathrm{ml} / \mathrm{kg} / \mathrm{min}$ and 7\%, respectively improvements and finally it shows the positive effectiveness of a high level of aerobic capacity on match play performance in soccer is shown by the studies (Apor, 1988; Wisloff et al., 1998).

In conclusion data show that we need to improve the protocol of the study in order to have more precise data. We propose that in other study it will be needed to have a control group in order to compare this data (control group who do not train) with those who train and to have the real improvement by the soccer training sessions. Therefore, the assessment of the soccer player's aerobic performance could be of interest for soccer coaches in order to evaluate and better programme their endurance training sessions.

\section{References}

Armstrong N, Welsman JR. (1994). Assessment and interpretation of aerobic fitness in children and adolescents. Exerc Sport Sci Rev 22: 435-476.

Apor P (1988). Successful formula for fitness training. In: Reilly T, Less A, Davids K, Murphy WJ, eds. Science and football. London: E \& FN Spon,:95-107.

Bangsbo J (1994). The physiology of soccer - with special reference to intense intermittent exercise. Acta Physiol Scand;15 (Suppl 619):1-156.

Helgerud J, Engen LC, Wisløff U, et al (2001). Aerobic endurance training improves soccer performance. Med Sci Sports Exerc;33:1925-31.

Malina RM, Bouchard C, Bar-Or O (2004). Growth, maturation, and physical activity. Champaign, IL: Human Kinetics.

Kemi OJ, Hoff J, Engen LC, et al (2003). Soccer specific testing of maximal oxygen uptake. J Sports Med Phys Fitness;43:139-44.

Jarani J and Spahi A (2014). Actual level of the physical activity in children in Tirana. School children 6-15 years old, Journal of Physical Activity and Sports 2(1), 81-85.

Le'ger LA, Mercier D, Gadoury C, et al (1988). The multistage 20 metre shuttle run test for aerobic fitness. J Sports Sci;6:93-101.

Le'ger L, Boucher R (1980). An indirect continuous running multistage field test: the Universite' de Montreal track test. Can J Appl Sport Sci ; 5:77-84.

Rowland TW. (2005). Children's exercise physiology. Champaign, IL: Human Kinetics.

Welsman JR, Armstrong N, Nevill AM, Winter EM, Kirby BJ. (1996). Scaling peak VO2 for differences in body size. Med Sci Sports Exerc 28:259-265.

Wisløff U, Helgerud J, Hoff J (1998). Strength and endurance of elite soccer players. Med Sci Sports Exerc 30:462-47. 